Article

\title{
The Bioactivity Study of Active Compounds in Wolffia globosa Extract for an Alternative Source of Bioactive Substances
}

\author{
Supannee Tipnee ${ }^{1, *}$, Aranya Jutiviboonsuk ${ }^{2}$ and Paveena Wongtrakul ${ }^{2, *}$ \\ 1 Graduate School, Huachiew Chalermprakiet University, Samut Prakan 10540, Thailand \\ 2 Faculty of Pharmaceutical Sciences, Huachiew Chalermprakiet University, Samut Prakan 10540, Thailand; \\ ongsri@yahoo.com \\ * Correspondence: supannee.tipnee@hotmail.com (S.T.); paveena_hcu@hotmail.com (P.W.)
}

Received: 3 September 2017; Accepted: 27 November 2017; Published: 30 November 2017

\begin{abstract}
Wolffia globosa is a small plant found in the lagoons in tropical zones. The aim of our study was to examine the biological compounds found in W. globosa and their activities. The substances in $W$. globosa were extracted, isolated, and their chemical structures ascertained by Fourier transform infrared (FT-IR) spectroscopy and proton nuclear magnetic resonance $\left({ }^{1} \mathrm{H}-\mathrm{NMR}\right)$ spectroscopy. The extract was tested for bioactivity, including antioxidant, anti-inflammatory, and cytotoxic activities. The results showed that the isolated compounds in fraction two were mainly $\beta$-sitosterol and stigmasterol. The sterols found in the extract were able to inhibit nitric oxide production in RAW 264.7 macrophage cells, which implied an anti-inflammatory activity. The extract was found to be non-toxic to human dermal fibroblast cells with an $\mathrm{IC}_{50}$ of $106.38 \pm 37.0 \mu \mathrm{g} / \mathrm{mL}$.
\end{abstract}

Keywords: Wolffia globosa; bioactivity; Lemnaceae; $\beta$-sitosterol; stigmasterol

\section{Introduction}

Wolffia globosa, belonging to Lemnaceae or duckweed family, is a tiny water plant known as Asian watermeal, or Khai Nam in Thailand [1]. W. globosa does not have a central root system. The leaves and stems are fused together, called a "frond" [2]. The frond is spherical to ellipsoid, 0.5-0.8 mm in length and $0.4-0.6 \mathrm{~mm}$ in width, and pale green on the surface [3]. W. globosa grows easily and quickly by budding with a generation time of approximately four days in controlled laboratory conditions [4]. Natural Wolffia spp. grows in Northern Thailand from July to November with an annual yield of 265 tons/hectare [5]. It is used as a vegetable in Burma, Laos, and Thailand, due to its high protein content of approximately $40 \%$ dry weight [6]. It also contains high amounts of chlorophyll, carotenoids, flavonoids, and vitamin $B_{12}$ [7], making it a suitable raw material for various industrial products such as animal feeds, alcohol, and even biodegradable plastics [1,8].

In general, duckweed contains about $20-35 \%$ protein of its dry weight, $4-7 \%$ fat, and $4-10 \%$ starch [8]. $\beta$-sitosterol and stigmasterol have been found in the ether extract of W. arrhiza [2]. Phytosterols are a subgroup of the steroid alcohol bearing resemblance in chemical structure to cholesterol and have been reported, and especially $\beta$-sitosterol, to possess antioxidant, antimicrobial, antiarthritic, and antinociceptive activities without major toxicity [9]. A few studies examined the chemical compositions of $W$. globosa. Nini et al. reported that glycosidic derivatives apigenin and luteolin were found in the ethanolic extract of W. globosa [10]. Based on the limited data about W. globosa, we attempted to examine its compounds and biological activities to determine if the extract might be used as an alternative source of bioactive substances. 


\section{Materials and Methods}

\subsection{Key Chemicals, Reagents and Cell Culture}

HDFn cell line (Gibco, C-0045C), 1,1-diphenyl-2-picrylhydrazyl (Sigma-Aldrich, St. Louis, MO, USA), ethanol, methanol (Merck, Darmstadt, Germany), dichloromethane (Fisher Scientific, Loughborough, UK), $\beta$-sitosterol $\geq 70 \%$ (Sigma-Aldrich, St. Louis, MO, USA), acetone, chloroform (VWR international S.A.S, France), hexane (J.T.Baker, Center Valley, PA, USA), ethyl acetate (J.T.Baker, Center Valley, PA, USA), sulfuric acid 98\% (RCI Labscan Ltd., Bangkok, Thailand), and vanillin 99\% (Sigma-Aldrich, St. Louis, MO, USA) were used in this study. All of the chemicals used were of analytical grade.

\subsection{Plant Materials}

The W. globosa was obtained from a harvesting wholesaler, who grew the duckweed under controlled cultivation, in Sansai, Chiangmai, Thailand. The plants were identified as Wolffia globosa (Roxb.) by Hartog and Plas at Queen Sirikit Botanic Garden Herbarium, Thailand. The respective voucher specimen (QBG 95804) was deposited there for future reference.

\subsection{Analytical Apparatus}

To perform the analysis in this study, a UV-Vis spectrophotometer (UV-1800, SHIMADZU, Kyoto, Japan), a Nuclear Magnetic Resonance Spectrometer (Avance III 400, Bruker, Billerica, MA, USA), Fourier Transform Infrared Spectroscopy (Spectrum100, Perkin Elmer ${ }^{\circledR}$, Waltham, MA, USA), and a Rotary Evaporator (Rotavapor ${ }^{\circledR}$ R-205, Buchi, Flawil, Switzerland) were used.

\subsection{Preparation of Ethanolic Extract}

A total of $10 \mathrm{~kg}$ of fresh W. globosa was rinsed with fresh water and dried under sunlight for 2-3 days before being mashed with mortar and pestle. The ethanolic extract was prepared by maceration of dried W. globosa powder $(672.15 \mathrm{~g})$ with $3 \mathrm{~L}$ of ethanol at room temperature for 1 day and the suspension was then filtered through filter paper (Whatman No. 1). The marc was re-extracted 30 times with the same method. The ethanolic extracts were pooled together and the solvent was removed under vacuum at $45{ }^{\circ} \mathrm{C}$ using a rotary evaporator. The crude ethanolic extract was stored at $-20{ }^{\circ} \mathrm{C}$ prior to analysis.

\subsection{Chromatographic Separation}

Thin layer chromatography (TLC) was used to investigate the compounds in the crude ethanolic extract. $\beta$-sitosterol and stigmasterol, as reference standards, were dissolved separately in chloroform and adjusted to $1 \%$ standard solution while the extract was dissolved in ethanol and adjusted to $10 \% w / v$. Sample solutions of $5 \mu \mathrm{L}$ and standard solutions of $3 \mu \mathrm{L}$ were spotted on silica gel 60 $\mathrm{F}_{254}$ pre-coated aluminum plates and the plate was developed in mobile phase consisting of acetone and hexane at a 20:60 ratio by volume [11]. The detection of sterols was performed by spraying the developed plate with 5\% sulfuric acid in ethanol followed by $1 \%$ vanillin in ethanol. After drying at room temperature, the plate was heated to $80-100{ }^{\circ} \mathrm{C}$ for $5 \mathrm{~min}$ [12]. In order to isolate the substances from the crude extract, column chromatography was then used with silica gel (mesh 0.04-0.06 mm, 230-400 mesh, $300 \mathrm{~g}$ ) as the stationary phase. Ten grams of crude ethanolic extract of W. globosa was dissolved in $20 \mathrm{~mL}$ hexane then filtered through Whatman No. 1 filter paper. The precipitate (WP1), weight $3.34 \mathrm{~g}$, was collected while the filtrate was applied on the column and sequentially eluted with $9 \mathrm{~L}$ hexane, 1.5 L dichloromethane, $2 \mathrm{~L}$ ethyl acetate, and $2 \mathrm{~L}$ methanol. The eluents were collected and gathered according to TLC data to obtain 4 fractions, labeled as WF1 to WF4. 


\subsection{Spectroscopic Characterization}

Fourier transform infrared (FT-IR) spectroscopy and proton nuclear magnetic resonance $\left({ }^{1} \mathrm{H}-\mathrm{NMR}\right)$ spectroscopy were used to determine the structure of the isolated compounds. The FT-IR spectrum was recorded using FT-IR Perkin Elmer, Spectrum 100. A small amount of fraction 2 (WF2) was placed directly on the diamond crystal plate of the Universal Attenuated Total Reflectance accessory (UATR) and then pressure was applied. The infrared absorbance data were collected over the wave range of 400 to $4000 \mathrm{~cm}^{-1}$. The computerized analysis was completed by the FT-IR spectrometer's spectrum software, while the ${ }^{1} \mathrm{H}-\mathrm{NMR}$ spectrum was recorded on Bruker Avance III (400 MHz) spectrometers, using $\mathrm{CDCl}_{3}$ as a solvent and tetramethylsilane as an internal standard. All chemical shifts $(\delta)$ were reported in ppm relative to the tetramethylsilane signal.

\subsection{Nitric Oxide Assay}

The nitric oxide assay was modified from the method previously reported by Torres-Rodríguez et al. [13]. RAW 264.7 macrophage cells were grown and incubated at $37{ }^{\circ} \mathrm{C}$ in a humidified incubator with a 5\% carbon dioxide $\left(\mathrm{CO}_{2}\right)$ atmosphere for $48 \mathrm{~h}$. After, $2 \times 10^{5}$ cells were seeded in a six-well plate and incubated at $37{ }^{\circ} \mathrm{C}$ in a $5 \% \mathrm{CO}_{2}$ atmosphere for $48 \mathrm{~h}$, the cells were then stimulated with lipopolysaccharides (LPS) and treated with different concentrations of BSS (a mixture of WF1 and WF2) between $0-1000 \mu \mathrm{g} / \mathrm{mL}$. The cells were further incubated at $37^{\circ} \mathrm{C}$ in a $5 \% \mathrm{CO}_{2}$ atmosphere for $24 \mathrm{~h}$, and then the nitrite content was measured as an indicator of nitric oxide production in the spent media, using Griess reaction. The $100-\mu \mathrm{L}$ cell culture medium was transferred into a 96-well plate and equal amounts of Griess reagent (1\% sulfanilamide and $0.1 \% \mathrm{~N}-1$-naphthyl ethylenediamine dihydrochloride in $2.5 \%$ phosphoric acid) were added. The plate was incubated at room temperature for 5 min and the absorbance at $550 \mathrm{~nm}$ was measured using a microplate reader. Fresh culture medium was used as the blank solution. The amount of released nitric oxide (NO) was calculated from a sodium nitrite standard curve.

\subsection{Cytotoxicity Against Human Dermal Fibroblast (HDFn)}

The cytotoxicity test procedure was modified from the method reported by O'Brien et al. [14]. The human dermal fibroblast (HDFn) cell line was isolated from neonatal foreskin. The isolated cells were grown and maintained in Dulbecco's Modified Eagle's Medium (DMEM), containing 10\% heat-inactivated fetal bovine serum, $2 \mathrm{mM}$ L-glutamine, $3.7 \mathrm{~g} / \mathrm{L}$ sodium bicarbonate, $100 \mathrm{unit} / \mathrm{mL}$ penicillin, and $100 \mu \mathrm{g} / \mathrm{mL}$ streptomycin, before incubation at $37^{\circ} \mathrm{C}$ in a humidified incubator with $5 \% \mathrm{CO}_{2}$. The cells at a logarithmic growth were harvested in 96-well plates and diluted to $3 \times 10^{4}$ cells $/ \mathrm{mL}$ in DMEM medium prior to assay in quadruplicate. The plates were seeded with $200 \mu \mathrm{L}$ of cell suspension or blank medium and incubated at $37^{\circ} \mathrm{C}$ in a humidified incubator with $5 \% \mathrm{CO}_{2}$ for $48 \mathrm{~h}$. Thereafter, the culture medium was replaced with $200 \mu \mathrm{L}$ of fresh medium containing different concentrations of crude ethanolic extract of W. globosa, ellipticine (the cytotoxic drug), or $1 \%$ dimethyl sulfoxide (DMSO), and the plates were further incubated for $24 \mathrm{~h}$. After the incubation period, $50 \mu \mathrm{L}$ of $125 \mu \mathrm{g} / \mathrm{mL}$ of resazurin solution was added to the plates and they were incubated at $37{ }^{\circ} \mathrm{C}$ in a humidified incubator with $5 \% \mathrm{CO}_{2}$ for $4 \mathrm{~h}$. The fluorometric measurement was determined using the bottom-reading mode at a $530 \mathrm{~nm}$ excitation wavelength and a $590 \mathrm{~nm}$ emission wavelength. The signal of the test wells was subtracted from that of blank well before calculation. The percentage of cytotoxicity was calculated according to the following equation:

$$
\% \text { Cytotoxicity }=\left[1-\left(\mathrm{FU}_{\mathrm{T}} / \mathrm{FU}_{\mathrm{C}}\right)\right] \times 100
$$

where $\mathrm{FU}_{\mathrm{T}}$ and $\mathrm{FU}_{\mathrm{C}}$ are the mean fluorescent unit from cells treated with test compound and $1 \%$ DMSO, respectively. The $\mathrm{IC}_{50}$ value was derived from the dose-response curve plotted between the percent cytotoxicity and the sample concentrations. 


\subsection{DPPH Free Radical Scavenging Activity}

The 1,1-diphenyl-2-picrylhydrazyl (DPPH) free radical scavenging assay was performed according to the modified method of Gülçin et al. [15]. All test samples were dissolved in ethanol to prepare the test sample solutions before evaluation of radical scavenging activity against DPPH. The test sample solutions, at volumes ranging from 0.1 to $0.5 \mathrm{~mL}$, were added into $2.5 \mathrm{~mL}$ of $0.1 \mathrm{mM}$ of DPPH in ethanol. The total volume of the mixture was adjusted to $3 \mathrm{~mL}$ with ethanol, so the final concentrations of the test samples were between $0.00-4.16 \mathrm{mg} / \mathrm{mL}$. The mixture was shaken by vortex mixer and then incubated at $30 \pm 3{ }^{\circ} \mathrm{C}$ for $30 \mathrm{~min}$. The absorbance was measured at the wavelength of $515 \mathrm{~nm}$ using a UV-Vis spectrophotometer. Ascorbic acid and ethanol were used as the reference and blank solutions, respectively. All tests were performed in triplicate. The scavenging activity was calculated as follows:

$$
\text { DPPH radical scavenging activity }(\%)=\left[\left(\text { O.D }_{\text {Control }}-\text { O.D Sample }\right) / O . D_{\text {Control }}\right] \times 100
$$

where O. $D_{\text {Control }}$ is the absorbance of the blank treated with no added extract and O.D $D_{\text {Sample }}$ is the absorbance in the presence of extract.

\section{Results and Discussion}

\subsection{Extraction and Chromatographic Separation by Thin Layer and Column Chromatography}

The percentage yield of the crude ethanolic extract of $W$. globosa was $0.82 \% w / w$. The crude extract was a dark green paste with a distinctive odor. TLC analysis of the crude W. globosa extract, developed in a slightly nonpolar solvent of acetone and hexane at a 20:60 ratio by volume, showed two main groups of compounds with different Rf values. The first group was less soluble in hydrophobic solvent and showed a smaller Rf value than that of the second group. The second group showed a Rf value of about 0.45 and had a purple to violet color with vanillin-sulfuric acid spraying reagent.

The results revealed that W. globosa extracts contained a large number of substances, including phytosterol, which appeared as purple to violet in color on the TLC plate after spraying with vanillin-sulfuric reagent. The spot with the Rf value of 0.45 corresponded to the $\beta$-sitosterol standard. $\beta$-sitosterol and stigmasterol are common phytosterols found in plants and are always available in a form of mixture [16]. These two substances can be differentiated at the $C_{22}-C_{23}$ bond, which is double bond for stigmasterol and single bond for $\beta$-sitosterol. Thus, the column chromatography was used to isolate the compounds. The crude W. globosa extract was instantly dissolved in hexane and then filtered to obtaining the $3.34 \mathrm{~g}$ of precipitate (WP1). The filtrate was applied on the column, obtaining 4 fractions: $0.07 \mathrm{~g}$ of fraction 1 (WF1) in hexane, $0.54 \mathrm{~g}$ of fraction 2 (WF2) in dichloromethane, $1.40 \mathrm{~g}$ of fraction 3 (WF3) in ethyl acetate, and $3.18 \mathrm{~g}$ of fraction 4 (WF4) in methanol. The TLC chromatogram of WF2 that was developed in acetone:hexane at a 20:60 ratio by volume showed a single spot at the same Rf value as the $\beta$-sitosterol standard (Figure 1). Thus, WF2 was further subjected to spectroscopic methods to determine the structure. 


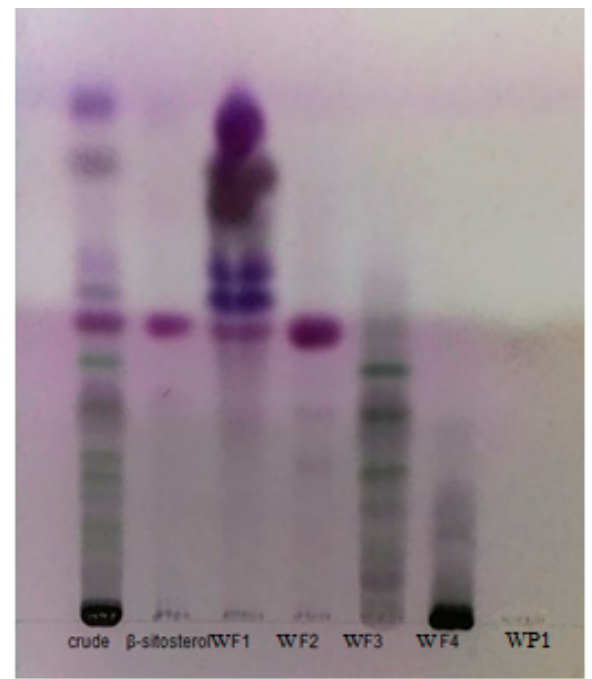

Figure 1. Thin layer chromatography (TLC) chromatogram of W. globosa extract developed in an acetone:hexane ratio of 20:60, sprayed with a vanillin-sulfuric agent.

\subsection{Spectroscopic Characterization by FT-IR and ${ }^{1} H-N M R$}

To confirm the chemical structure of the isolated compound, WF2 was subjected to identification by FT-IR and ${ }^{1} \mathrm{H}-\mathrm{NMR}$ spectroscopy. The FT-IR spectrum of the isolated compound showed absorption bands at $3318.9 \mathrm{~cm}^{-1}$ characteristic of $\mathrm{O}-\mathrm{H}$ stretching, and also at $2936.31 \mathrm{~cm}^{-1}$ and $2865.07 \mathrm{~cm}^{-1}$ characteristic of aliphatic $\mathrm{C}-\mathrm{H}$ stretching. Other absorption frequencies were observed at $1635.24 \mathrm{~cm}^{-1}$ for $\mathrm{C}=\mathrm{C}$ stretching, a bending frequency at $1462.35 \mathrm{~cm}^{-1}$ for cyclic $\left(\mathrm{CH}_{2}\right)_{\mathrm{n}}$, and $1378.29 \mathrm{~cm}^{-1}$ for $-\mathrm{CH}_{2}\left(\mathrm{CH}_{3}\right)_{2}$. The absorption frequency at $1044.60 \mathrm{~cm}^{-1}$ signifies cycloalkane. All of these absorption bands signified the structure of $\beta$-sitosterol. The observed peak at $800.66 \mathrm{~cm}^{-1}$ is a frequency resembling the absorption of stigmasterol, which was observed in WF2 as well. The obtained data were comparable to the spectral of Ageratum conyzoides [Asteraceae] extract previously reported [17], in which IR peaks were observed at 3373.6, 2940.7, 2867.9, 1641.6, 1457.3, 1381.6, 1038.7, and $881.6 \mathrm{~cm}^{-1}$. They were identified as $\beta$-sitosterol and stigmasterol.

Furthermore, the ${ }^{1} \mathrm{H}-\mathrm{NMR}$ spectra of WF2 had the following signals at $400 \mathrm{MHz}, \mathrm{CDCl}_{3}$,

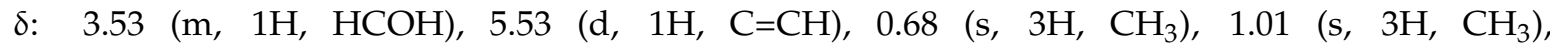
$0.93\left(\mathrm{~d}, 3 \mathrm{H}, \mathrm{CH}_{3}\right), 0.83\left(\mathrm{~d}, 3 \mathrm{H}, \mathrm{CH}_{3}\right), 0.79\left(\mathrm{~d}, 3 \mathrm{H}, \mathrm{CH}_{3}\right), 0.85\left(\mathrm{t}, 3 \mathrm{H}, \mathrm{CH}_{3}\right), 5.12(\mathrm{dd}, 1 \mathrm{H}, \mathrm{C}=\mathrm{CH})$, $5.02(\mathrm{dd}, 1 \mathrm{H}, \mathrm{C}=\mathrm{CH})$, and $1.05-2.32$ (others). The ${ }^{1} \mathrm{H}-\mathrm{NMR}$ spectra of WF2 showed the proton of $\mathrm{H}-3$ as a multiplet at $\delta 3.53 \mathrm{ppm}$ and the existence of signals for olefinic proton at $\delta 5.12(\mathrm{dd})$, 5.02 (dd), which were identical to the chemical shift of H-22 and H-23 of stigmasterol, respectively. Angular methyl proton at $\delta 0.68$ (s) and 1.01 (s) corresponded to H-18 and H-19 protons, respectively. In addition, the three-proton doublet at $\delta 0.93$ (d), 0.83 (d), and 0.79 (d) corresponded to H-21, $\mathrm{H}-26$, and H-27, respectively, and another three-proton triplet at $\delta 0.85(\mathrm{t})$ could be assigned to $\mathrm{H}$-29. This result implies both $\beta$-sitosterol and stigmasterol were present in WF2 (Figure 2) $[17,18]$. 


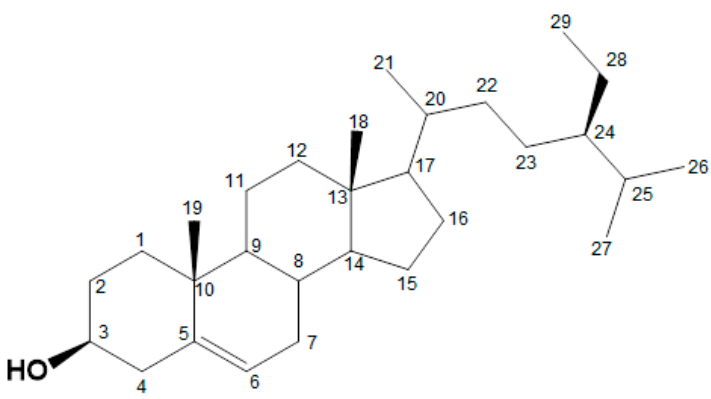

(a)

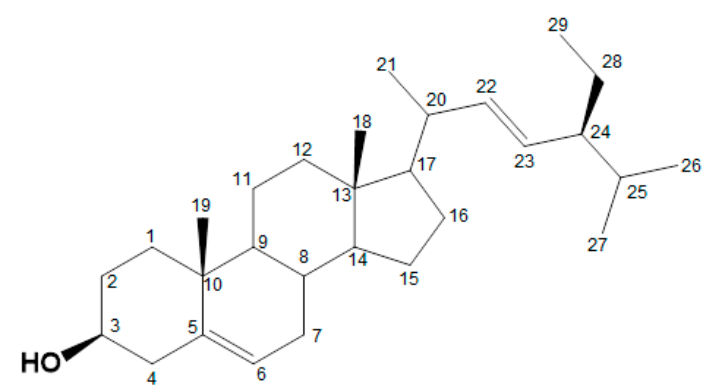

(b)

Figure 2. Structure of (a) $\beta$-sitosterol and (b) stigmasterol.

\subsection{Nitric Oxide Assay}

One of the effective ways to screen various anti-inflammatory substances is through the determination of an inhibition of NO production in LPS-stimulated murine macrophages (RAW 264.7 cell line) [19,20], since the release of NO in living cells is generally induced by inflammatory cytokines or bacterial LPS. Therefore, the anti-inflammatory activity of the W. globosa fraction was investigated by measuring nitrite levels found in the medium system of RAW 264.7 cells treated with LPS. The different concentrations of BSS, which showed spots belonging to a steroidal nucleus on the TLC plates, were used as the testing substance, while triamcinolone acetonide (TA), a steroidal drug, was used as the positive control. Table 1 shows the inhibitory activity of BSS and the positive control on NO production. The final concentration of BSS at 1 and $10 \mu \mathrm{g} / \mathrm{mL}$ showed effective inhibition of NO production at $13.01 \pm 1.48 \%$ and $16.84 \pm 1.81 \%$, respectively. Meanwhile, the corresponding concentration of the positive control (TA) showed $14.74 \pm 2.02 \%$ and $15.93 \pm 5.13 \%$ inhibition, respectively. Anti-inflammatory activity, via the inhibition of nitric oxide production, might be as a result of the existence of the sterol compounds in W. globosa. Due to the purification by our fractionation method, the active compounds in W. globosa showed an activity level comparable to triamcinolone acetonide.

Table 1. Inhibitory activity of the sterol fraction (BSS) and triamcinolone acetonide (TA) of nitric oxide (NO) production in lipopolysaccharide (LPS)-stimulated RAW 264.7 macrophages.

\begin{tabular}{cccccc}
\hline Sample & \multicolumn{5}{c}{ \% Nitric Oxide Inhibition at Various Concentrations $(\boldsymbol{\mu g} / \mathbf{m L})$} \\
\hline & 0.1 & 1 & 10 & 100 & 1000 \\
BSS & $-17.70 \pm 3.84$ & $13.01 \pm 1.48$ & $16.84 \pm 1.81$ & $5.97 \pm 2.22$ & $5.65 \pm 3.52$ \\
TA & $9.73 \pm 2.81$ & $14.75 \pm 2.02$ & $15.93 \pm 5.13$ & $16.52 \pm 4.45$ & $18.88 \pm 3.90$ \\
\hline
\end{tabular}

\subsection{Cytotoxicity Against Human Dermal Fibroblast (HDFn)}

Cell cytotoxicity assays have been widely used to evaluate toxicity of substances extracted from natural sources before investigating their development as active raw materials [21]. The compounds that have cytotoxic effects can cause a variety of cell fates. Cells will lose membrane integrity and die rapidly as a result of cell lysis. Cytotoxicity can be monitored by dyes to indicate the redox potential of viable cells. In this study, the viable cells reduced the resazurin reagent to a fluorescent resorufin product [14]. The toxicity of crude ethanolic W. globosa extract was tested against human dermal fibroblast neonatal (HDFn). Ellipticine, the known anti-cancer drug, was used as a positive control. After adding the $W$. globosa extract, resazurin was incubated on the cell line. The culture media was then measured for resorufin by using the fluorometric technique. The cytotoxicity percentages of the testing samples are summarized in Table 2. The result showed that all studied concentrations $(0-100 \mu \mathrm{g} / \mathrm{mL})$ of $W$. globosa extract were less toxic to HDFn cells, with an $\mathrm{IC}_{50}$ of $106.38 \pm 37.0 \mu \mathrm{g} / \mathrm{mL}$, while ellipticine had cytotoxic activity with an $\mathrm{IC}_{50}$ of $4.00 \pm 3.7 \mu \mathrm{g} / \mathrm{mL}$. According to the cytotoxicity 
activity criteria crude extracts, as established by the American National Cancer Institute, an $\mathrm{IC}_{50}$ of less than $30 \mu \mathrm{g} / \mathrm{mL}$ is considered to be cytotoxic [22].

Table 2. Cytotoxicity study of W. globosa crude extract and ellipticine on human dermal fibroblast neonatal (HDFn) cell line.

\begin{tabular}{ccccc}
\hline \multirow{2}{*}{ Sample } & Concentration $(\mu \mathrm{g} / \mathrm{mL})$ & \multicolumn{2}{c}{ Fluorescence Unit } & \multirow{2}{*}{ Cytotoxicity (\%) } \\
\cline { 3 - 4 } & & Average & SD & \\
\hline \multirow{2}{*}{ Ellipticine } & 0.00 & 6091 & 295 & 0.00 \\
& 0.313 & 5564 & 515 & 8.65 \\
& 0.625 & 4875 & 392 & 19.97 \\
& 1.25 & 4330 & 568 & 28.91 \\
& 2.50 & 3875 & 142 & 36.38 \\
& 5.00 & 1961 & 270 & 67.81 \\
& 10.00 & 36 & 16 & 99.41 \\
\hline Wlobosa extract & 0.00 & 6091 & 295 & 0.00 \\
& 3.13 & 5621 & 362 & 7.72 \\
& 6.25 & 4351 & 449 & 28.57 \\
& 12.50 & 4499 & 171 & 26.14 \\
& 25.00 & 4023 & 324 & 33.94 \\
& 50.00 & 3759 & 385 & 38.28 \\
& 100.00 & 3368 & 172 & 44.71 \\
\hline
\end{tabular}

\subsection{DPPH Radical Scavenging Assay}

A number of bioactive compounds in plants have been known to have antioxidant activity. In this study, the DPPH free radical scavenging assay was used to determine the antioxidant capacity of the W. globosa extract. The ethanolic solution of DPPH appears deep violet, which can be detected by UV-Vis spectroscopy at $515 \mathrm{~nm}$. The reduced form of DPPH can be instantly obtained when a sample is mixed with electron-donating substances, such as free radical scavengers [23,24]. The results showed the fractionated samples of WF1 and WF2 had very low scavenging activity, while the crude ethanolic extract, WP1, WF3, and WF4 had the ability to scavenge DPPH (Table 3). WP1 had scavenging activity with an $\mathrm{IC}_{50}$ of $2.70 \mathrm{mg} / \mathrm{mL}$. The free radical scavengers available in the $W$. globosa extract were hydrophilic compounds, which were precipitated in hexane and eluted with polar solvent as ethyl acetate and methanol. This result corresponded to the previous report that flavones were found in $W$. globosa. Thus, the scavenging activity of $W$. globosa might be as a result of the activity of flavonoids in the W. globosa extract. Moreover, other types of duckweed, such as L. minor, were also reported to have antioxidant activity. This activity has been attributed to the phenolic compounds and flavonoids in the extract [15].

Table 3. 1-diphenyl-2-picrylhydrazyl (DPPH) radical scavenging activity (\%) of W. globosa extract at different concentrations.

\begin{tabular}{ccccccc}
\hline \multirow{2}{*}{ Concentration mg/mL } & \multicolumn{7}{c}{ Radical Scavenging Activity (\%) } \\
\cline { 2 - 7 } & Crude Extract & WP1 & WF1 & WF2 & WF3 & WF4 \\
\hline 0.06 & $3.47 \pm 0.10$ & $2.12 \pm 0.04$ & $0.13 \pm 0.03$ & $0.26 \pm 0.04$ & $2.56 \pm 0.05$ & $0.96 \pm 0.05$ \\
0.13 & $5.53 \pm 0.10$ & $2.75 \pm 0.01$ & $1.07 \pm 0.02$ & $1.31 \pm 0.08$ & $3.52 \pm 0.06$ & $1.48 \pm 0.05$ \\
0.20 & $8.72 \pm 0.08$ & $3.87 \pm 0.05$ & $1.15 \pm 0.06$ & $1.28 \pm 0.02$ & $5.48 \pm 0.03$ & $2.30 \pm 0.05$ \\
0.27 & $10.70 \pm 0.73$ & $4.90 \pm 0.08$ & $1.17 \pm 0.05$ & $1.45 \pm 0.03$ & $6.72 \pm 0.60$ & $3.71 \pm 0.01$ \\
0.34 & $13.94 \pm 0.06$ & $7.26 \pm 0.04$ & $0.88 \pm 0.02$ & $2.12 \pm 0.03$ & $7.38 \pm 0.07$ & $5.06 \pm 0.04$ \\
\hline
\end{tabular}

The antioxidant and anti-inflammatory activities of W. globosa, as first investigated in this study, document the capability of this duckweed genus as an alternative active compound for medicinal and cosmetic applications. Several studies have reported on the pharmacological activities of giant 
duckweed, Spirodela polyrhiza (L.) Sch., ethanolic extract, used in Eastern herbal medicine, with respect to inhibition of $\mathrm{NO}$ production and some inflammatory mediators in a concentration-dependent manner in a murine macrophage cell line [25]. As a consequence of this experimental finding of the underlying mechanisms of the anti-inflammatory activities of this Korean traditional duckweed, the topical application of ethanolic extract of Spirodela polyrhiza (L.) Sch. was reported to improve atopic dermatitis [26]. The clinical implication of the use of duckweeds has revealed some interesting aspects regarding its nutritive value, large-scale yield, and economical and sustainable market supply [5]. Based on the limited data of W. globosa, the antioxidant activity was investigated and was found to be highly correlated with phenolic contents, as reported by Daduang [27]. Recently, a detailed investigation of the nutritive compositions of six duckweed species [28] emphasized that the phytosterol content in Wolffia microscopica $\left(50 \mathrm{mg} /{ }^{1} \mathrm{fat}\right)$ was at least five-fold higher than in most other plant oils, which typically contain 1-10 mg/g fat. The main components were sitosterol (53\%), campesterol $(18 \%)$, and stigmasterol $(15 \%)$ followed by D5-avenasterol (11\%). Sitosterol content appeared to be determined by the species, as observed from the investigations on W. arrhiza by Kotowska [2]. Duckweeds seem to be one of the plants having a high phytosterol content. Additionally, W. microscopica also contained carotenoids and tocopherols as antioxidants. Here, the anti-inflammatory and antioxidant activities of $W$. globosa are as a result of the presence of phytosterols, carotenoids, and tocopherols.

\section{Conclusions}

W. globosa has been known as one of the smallest aquatic plants, which is commonly found in natural water sources in Thailand. The isolated compounds eluted from column chromatography were mainly phytosterols, which were a mixture of $\beta$-sitosterol and stigmasterol. Due to the existence of the sterol substances, the $W$. globosa extract was able to inhibit nitric oxide production. Its inhibitory activity was comparable to that of triamcinolone acetonide. Moreover, the hydrophilic substances in the W. globosa extract were found to have antioxidant activity against DPPH radicals. In this study, the W. globosa extract was not toxic to the human dermal fibroblast (HDFn) cells. Therefore, we conclude that $W$. globosa has interesting biological activities that could potentially be used as a source of bioactive compounds, such as antioxidants or anti-inflammatory effects, in either food or cosmetic products.

Acknowledgments: The authors thank Queen Sirikit Botanic Garden Herbarium, Thailand for supporting voucher specimens in this article. The authors did not receive funds to support present research work or to cover the costs to publish in open access.

Author Contributions: Supannee Tipnee and Aranya Jutiviboonsuk designed the experiments and performed the experiments; Supannee Tipnee and Paveena Wongtrakul analyzed the data and wrote the paper.

Conflicts of Interest: The authors declare no conflict of interest.

\section{References}

1. Chantiratikul, A.; Pooponpan, P.; Santhaweesuk, S.; Chantiratikul, P.; Sangdee, A.; Maneechote, U.; Bunchasak, C.; Chinrasri, O. Effect of Wolffia meal [Wolffia globosa (L). Wimm.] as a dietary protein replacement on performance and carcass characteristics in broilers. Int. J. Poult. Sci. 2010, 9, 664-668.

2. Kotowska, U.; Piotrowska, A.; Isidorova, A.; Bajguz, A.; Isidorov, V. Gas chromatographic-mass spectrometric investigation of the chemical composition of the aquatic plant Wolffia arrhiza (Lemnaceae). Oceanol. Hydrobiol. Stud. 2013, 42, 181-187. [CrossRef]

3. Landolt, E. Taxonomy and Ecology of the Section Wolffia of the genus Wolffia (Lemnaceae); Veröffentlichungen des Geobotanischen Institutes der ETH, Stiftung Rübel, Zürich: Zürich, Switzerland, 1994; Volume 60, pp. 137-151.

4. Ruekaewma, N. Optimal conditions for Production of Khai-Nam Wolffia globosa. Ph.D. Thesis, Chulalongkorn University, Bangkok, Thailand, 2011.

5. Bhanthumnavin, K.; McGarry, M.G. Wolffia arrhiza as a possible source of inexpensive protein. Nature 1971, 232, 495. [CrossRef] [PubMed] 
6. Kirjakov, I.; Katya, V. Wolffia globosa (Roxburgh) Hartog Et Plas (Lemnaceae): A new species in Bulgarian flora. J. Biolobical. Sci. Opin. 2013, 1, 356-357.

7. Szamrej, I.K.; Czerpak, R. The effect of sex steroids and corticosteroids on the content of soluble proteins, nucleic acids and reducing sugars in Wolffia arrhiza (L.) Wimm. (Lemnaceae). Pol. J. Environ. Stud. 2004, 13, 565-571.

8. Klaus, J.; Appenroth, K.; Sree, S. Duckweed for human nutrition. Newsl. Community Duckweed Res. Appl. 2016, 4, 313-314.

9. Woyengo, T.A.; Ramprasath, V.R.; Jones, P.J.H. Anticancer effects of phytosterols. Eur. J. Clin. Nutr. 2009, 63, 813-820. [CrossRef] [PubMed]

10. Nini, W.; Yang, F.; Tao, Y.; Guoyou, L.; Hai, Z. Chemical constituents of Wolffia globosa. Chin. J. Appl. Environ. Biol. 2014, 20, 1016-1019.

11. Mittal, S. Thin layer chromatography and high pressure liquid chromatography profiling of plant extracts of Viola odorata Linn. Int. J. Pharma Bio Sci. 2013, 4, 542-549.

12. Boukes, G.J.; van de Venter, M.; Oosthuizen, V. Quantitative and qualitative analysis of sterols/sterolins and hypoxoside contents of three Hypoxis (African potato) spp. Afr. J. Biotechnol. 2008, 7, 1624-1629.

13. Torres-Rodríguez, M.L.; García-Chávez, E.; Berhow, M.; de Mejia, E.G. Anti-inflammatory and anti-oxidant effect of Calea urticifolia lyophilized aqueous extract on lipopolysaccharide-stimulated RAW 264.7 macrophages. J. Ethnopharmacol. 2016, 188, 266-274. [CrossRef] [PubMed]

14. O'Brien, J.; Wilson, I.; Orton, T.; Pognan, F. Investigation of the Alamar Blue (resazurin) fluorescent dye for the assessment of mammalian cell cytotoxicity. Eur. J. Biochem. 2000, 267, 5421-5426. [CrossRef] [PubMed]

15. Gülçin, İ.; Kirecci, E.; Akkemik, E.; Fevzi, T.; Hisar, O. Antioxidant, antibacterial, and anticandidal activities of an aquatic plant: Duckweed (Lemna minor L. Lemnaceae). Turkish J. Biol. 2010, 34, 175-188.

16. Pierre, L.L.; Moses, M.N. Isolation and characterisation of stigmasterol and $\beta$-sitosterol from Odontonema strictum (Acanthaceae). J. Innov. Pharm. Biol. Sci. 2015, 2, 88-95.

17. Komboj, A.; Saluja, A.K. Isolation of stigmasterol and $\beta$-sitosterol from petroleum ether extract of aerial parts of Ageratum conyzoides (Asteraceae). Int. J. Pharm. Pharm. Sci. 2011, 3, 94-96.

18. Sen, A.; Dhavan, P.; Shukla, K.K.; Singh, S.; Tejovathi, G. Analysis of IR, NMR and antimicrobial activity of $\beta$-sitosterol isolated from Momordica charantia. Sci. Secur. J. Biotechnol. 2012, 1, 9-13.

19. Joo, T.; Sowndhararajan, K.; Hong, S.; Lee, J.; Park, S.Y.; Kim, S.; Jhoo, J.W. Inhibition of nitric oxide production in LPS-stimulated RAW 264.7 cells by stem bark of Ulmus pumila L. Saudi J. Biol. Sci. 2014, 21, 427-435. [CrossRef] [PubMed]

20. Sudsai, T.; Wattanapiromsakul, C.; Tewtrakul, S. Inhibition of nitric oxide production by compounds from Boesenbergia longiflora using lipopolysaccharide-stimulated RAW264.7 macrophage cells. Songklanakarin J. Sci. Technol. 2013, 35, 317-323.

21. Ifeoma, O.; Oluwakanyinsola, S. Screening of herbal medicines for potential toxicities. In New Insights into Toxicity and Drug Testing; InTech: London, UK, 2013.

22. Intarat, A.; Houghton, P.J.; Eno-Amooquaye, E.; Burke, P.J.; Sampson, J.H.; Raman, A. In vitro cytotoxic activity of Thai medicinal plants used traditionally to treat cancer. J. Ethnopharmacol. 2004, 90, 33-38.

23. Alam, N.; Bristi, N.J.; Rafiquzzaman, M.D. Review on in vivo and in vitro methods evaluation of antioxidant activity. Saudi Pharm. J. 2013, 21, 143-152. [CrossRef] [PubMed]

24. Huang, D.; Ou, B.; Prior, R.L. The chemistry behind antioxidant capacity assays. J. Agric. Food chem. 2005, 53, 1841-1856. [CrossRef] [PubMed]

25. Seo, C.S.; Lee, M.Y.; Shin, I.S.; Lee, J.A.; Ha, H.; Shin, H.K. Spirodela polyrhiza (L.) Sch. ethanolic extract inhibits LPS-induced inflammation in RAW264.7 cells. Immunopharmacol. Immunotoxicol. 2012, 34, 794-802. [CrossRef] [PubMed]

26. Lee, H.J.; Kim, M.H.; Choi, Y.Y.; Kim, E.H.; Hong, J.; Kim, K.; Yang, W.M. Improvement of a topic dermatitis with topical application of Spirodela polyrhiza. J. Ethnopharmacol. 2016, 180, 12-17. [CrossRef] [PubMed] 
27. Daduang, J.; Vichitphan, S.; Daduang, S.; Hongsprabhas, P.; Boonsiri, P. High phenolics and antioxidants of some tropical vegetables related to antibacterial and anticancer activities. Afr. J. Pharm. Pharmacol. 2011, 5, 608-615. [CrossRef]

28. Appenroth, K.J.; Sree, K.S.; Böhm, V.; Hammann, S.; Vetter, W.; Leiterer, M.; Jahreis, G. Nutritional value of duckweeds (Lemnaceae) as human food. Food Chem. 2017, 217, 266-273. [CrossRef] [PubMed]

(c) (c) 2017 by the authors. Licensee MDPI, Basel, Switzerland. This article is an open access article distributed under the terms and conditions of the Creative Commons Attribution (CC BY) license (http://creativecommons.org/licenses/by/4.0/). 